\title{
High-performance liquid chromatography and derivative spectrophotometry for simultaneous determination of pravastatin and fenofibrate in the dosage form
}

\author{
MOHAMED M. HEFNAWY \\ MOSTAFA S. MOHAMED \\ MOHAMMED A. ABOUNASSIF \\ AMER M. ALANAZI \\ GAMAL A. E. MOSTAFA* \\ Pharmaceutical Chemistry \\ Department, College of Pharmacy \\ King Saud University, P.O. Box 2457 Riyadh \\ 11451, Saudi Arabia
}

\begin{abstract}
High performance liquid chromatography (HPLC) and second-order derivative spectrophotometry have been used for simultaneous determination of pravastatin (PS) and fenofibrate (FF) in pharmaceutical formulations. HPLC separation was performed on a phenyl HYPERSIL C18 column ( $125 \mathrm{~mm} \times 4.6 \mathrm{~mm}$ i.d., $5 \mu \mathrm{m}$ particle diameter) in the isocratic mode using a mobile phase acetonitrile $/ 0.1 \%$ diethyl amine (50:50, $V / V, \mathrm{pH} 4.5)$ pumped at a flow rate of 1.0 $\mathrm{mL} \mathrm{min}^{-1}$. Measurement was made at $240 \mathrm{~nm}$. Both drugs were well resolved on the stationary phase, with retention times of 2.15 and $5.79 \mathrm{~min}$ for PS and FF, respectively. Calibration curves were linear $(R=0.999$ for PS and 0.996 for $\mathrm{FF}$ ) in the concentration range of $5-50$ and $20-200 \mu \mathrm{g} \mathrm{mL}^{-1}$ for PS and FF, respectively.

Pravastatin and fenofibrate were quantitated in combined preparations also using the second-order derivative response at 237.6 and $295.1 \mathrm{~nm}$ for PS and FF, respectively. Calibration curves were linear, with the correlation coefficient $R=0.999$ for pravastatin and fenofibrate, in the concentration range of $5-20$ and $3-20 \mu \mathrm{gL}^{-1}$ for PS and FF, respectively. Both methods were fully validated and compared, the results confirmed that they were highly suitable for their intended purpose.
\end{abstract}

Keywords: pravastatin, fenofibrate, spectrophotometry, HPLC, dosage form

Pravastatin is a member of the drug class of statins, used in combination with diet, exercise, and weight-loss for lowering cholesterol and preventing cardiovascular diseases (1). Its chemical structure is: (3R,5R)-3,5-dihydroxy-7-((1R,2S,6S,8R,8aR)-6-hydroxy-2-methyl-8-\{[(2S)-2-methylbutanoyl]oxy\}-1,2,6,7,8,8a-hexahydronaphthalen-1-yl)-heptanoic acid (Fig. 1).

\footnotetext{
*Correspondence; e-mail: gamal_most@yahoo.com
} 
Fenofibrate is mainly used to reduce cholesterol levels in patients at risk of cardiovascular diseases. Like other fibrates, it reduces the levels of both low-density lipoprotein (LDL) and very low density lipoprotein (VLDL) increases high-density lipoprotein (HDL) and reduces triglyceride (TG) levels. It is used alone or in conjunction with statins in the treatment of hypercholesterolemia and hypertriglyceridemia. Its chemical name is: propan2-yl-2-\{4-[(4-chlorophenyl)carbonyl]phenoxy\}-2-methylpropanoate (Fig. 1).
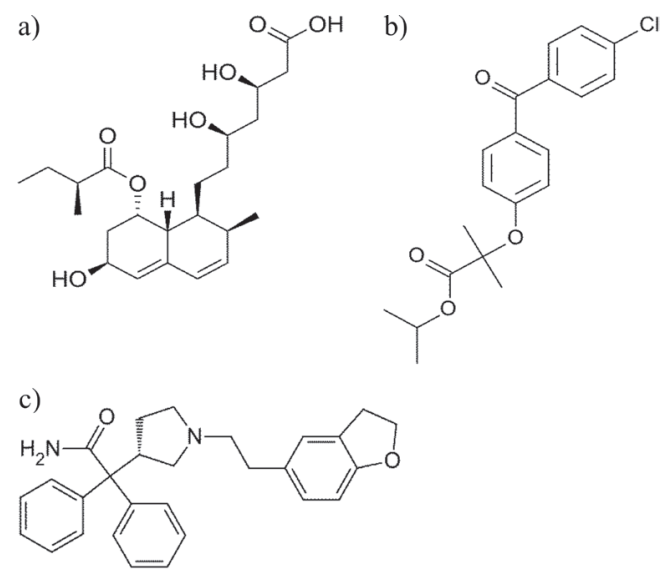

Fig. 1. Chemical structures of: a) pravastatin, b) fenofibrate and c) darifenacin (IS).

A combination dosage form of pravastatin and fenofibrate (Pravafenix capsule) is indicated for the treatment of high coronary heart disease-risk adult patients with mixed dyslipidaemia characterized by high TG and high LDL levels, whose LDL levels are adequately controlled while on a treatment with pravastatin $40 \mathrm{mg}$ monotherapy (2).

Various methods cited in the literature for determination of pravastatin involved high performance liquid chromatography HPLC-UV (3-5), HPLC-mass spectrometry (HPLCMS) (6-9) and voltammetry (10). Fenofibrate is official in USP (11) and BP (12) but different methods have been cited in the literature for determination of fenofibrate involving HPLCUV $(13,14)$ and HPLC-MS (15), voltammetry (16) and differential pulse polarographic techniques (17). A stability indicating UPLC method for simultaneous determination of atorvastatin, fenofibrate and their impurities in tablets was developed and validated (14). Chromatographic separation was performed on the reversed phase stationary phase using gradient elution. No HPLC or spectrophotometric method has been reported in the literature for simultaneous determination of pravastatin and fenofibrate in their commercial formulations. However, a HPLC and second-derivative spectrophotometry have been applied to analysis of atorvastatin and fenofibrate in combined tablets $(18,19)$. Therefore, the present work describes two analytical procedures for the quantitation of pravastatin and fenofibrate in their single dosage form using reversed phase HPLC and second-derivative spectrophotometry. 
M. M. Hefnawy et al.: High-performance liquid chromatography and derivative spectrophotometry for simultaneous determination of pravastatin and fenofibrate in the dosage form, Acta Pharm. 64 (2014) 433-446.

\section{EXPERIMENTAL}

\section{Reagents and materials}

Pravastatin (> $99 \%$ purity) and fenofibrate (> $99 \%$ purity) were obtained from Sigma Co. (Germany). Darifenacin hydrobromide (> $99 \%$ purity) to be used as IS was purchased from Novartis International Pharmaceutical Ltd. (Ireland). Structures of the standards are given in Fig. 1. HPLC-grade acetonitrile and analytical grade diethyl amine and ortho-phosphoric acid were purchased from BDH Chemicals (UK). Bidistilled water was purified using a cartridge system and ultra pure water of $5.56 \times 10^{-8} \mathrm{~S}$ was obtained from a Milli-Q plus purification system, Millipore (Waters, USA).

\section{Apparatus}

The HPLC analysis was carried out on a Waters HPLC system (USA) equipped with a 1500 series HPLC pump, operating at a flow rate of $1.0 \mathrm{~mL} \mathrm{~min}^{-1}$. A dual wavelength UVVisible detector (2475) and an autosampler (717 plus) were used. Data was collected with an Empower pro Chromatography Manager for data acquisition and analysis. Chromatographic separations were performed with an analytical column phenyl HYPERSIL C18 (125 $\mathrm{mm} \times 4.6 \mathrm{~mm}$ i.d., $5-\mu \mathrm{m}$ particle diameter) manufactured by Thermo electron corporation (USA), coupled with a symmetry C18-Sentry guard column $(20 \mathrm{~mm})$. All solutions were degassed by ultrasonication (Technal, Brazil) and filtered through a 0.45- $\mu$ m Millex filter (Millipore, Waters).

A Shimadzu UV/VIS spectrophotometer, Model 1800 (Japan), was used for measuring the absorbance and recording normal and derivative spectra.

\section{Chromatographic conditions}

The mobile phase consisted of acetonitrile and $0.1 \%$ diethyl amine $(50: 50, \mathrm{~V} / \mathrm{V}, \mathrm{pH}=$ 4.5). The mobile phase was freshly prepared, then filtered and degassed. All separations were performed isocratically at a flow rate of $1 \mathrm{~mL} \mathrm{~min}^{-1}$. Column temperature was maintained at $25 \pm 2{ }^{\circ} \mathrm{C}$. The injection volume was $10 \mu \mathrm{L}$, and the detection wavelength was set at $240 \mathrm{~nm}$.

\section{Measurement of derivative spectra}

Standard solutions of PS and FF were appropriately diluted with methanol to obtain solutions containing $10 \mathrm{mg} \mathrm{mL}^{-1}$ of PS and FF. These solutions were scanned in the region 200-350 nm against methanol as blank. The zero-order spectra of PS and FF were treated to obtain the corresponding second-order derivative spectra using $\Delta \lambda=4 \mathrm{~nm}$ and scaling factor 16. Independent recordings of the spectra were carried out in triplicate. Distances $h_{1}$ and $h_{2}$ for PS and FF at 237.6 and $295.1 \mathrm{~nm}$, respectively, were recorded in the derivative spectra (see below), and the concentration of each compound was calculated from the pre-constructed calibration graph.

\section{Standard solutions}

HPLC. - Stock solutions of pravastatin and fenofibrate were prepared by dissolving an appropriate amount of each compound in methanol to yield concentrations of 1.0 and 
$4.0 \mathrm{mg} \mathrm{mL}^{-1}$, resp. Working standard solutions were prepared by dilution with methanol to give 100 and $400 \mu \mathrm{g} \mathrm{mL}^{-1}$ of PS and FF, respectively. The standard solution of darifenacin as internal standard (IS) $\left(1.0 \mathrm{mg} \mathrm{mL}^{-1}\right)$ was also prepared in methanol. The concentration of IS was maintained at $100 \mu \mathrm{g} \mathrm{mL}^{-1}$ in each combined solution of PS and FF used for quantitative studies. Stock solutions of 1 and $4 \mathrm{mg} \mathrm{mL}^{-1}$ were stable for at least one month when stored in refrigerator $\left(4^{\circ} \mathrm{C}\right)$ with no evidence of degradation in the chromatograms during that period.

Spectrophotometry. - Stock solutions of pravastatin and fenofibrate were prepared by accurate weighing of each and dissolving in methanol. The concentration of $200 \mu \mathrm{gL} \mathrm{m}^{-1}$ was prepared in methanol after dilution. For simultaneous quantitative studies of both the drugs, a series of standard solutions containing both drugs were prepared by appropriate dilution of a mixture of stock solutions.

\section{Samples}

Twenty capsules (Pravafenix ${ }^{\circledR}$ capsule, Laboratoires SMB s.a., Belgium) (each capsule containing 40 PS plus $160 \mathrm{mg}$ of FF) were emptied, the contents were ground and mixed well to a fine powder. An accurately weighed portion of the powder equivalent to 40 and $160 \mathrm{mg}$ of PS and FF, resp., was placed into a $100-\mathrm{mL}$ volumetric flask. About $30 \mathrm{~mL}$ of methanol was added to that flask and sonicated in an ultrasonic bath for $5 \mathrm{~min}$. This solution was then diluted to the mark with methanol and mixed. It was then filtered through a $0.22 \mu \mathrm{m}$ nylon filter and the filtrate was collected after discarding the first few milliliters. Different sample solutions of required concentrations were prepared using the filtrate.

For laboratory prepared sample $4.0 \mathrm{mg}$ of PS and $16.0 \mathrm{mg}$ of FF were added to the tablet powder (containing Mg-stearate, calcium hydrogenphosphate, silicon dioxide, starch and cellulose), finely powered, and transferred into a 100-mL calibrated flask, and then 40 $\mathrm{mL}$ of distilled water was added. The contents of the flask were swirled and sonicated for 15 minutes. The contents were completed to the mark with water, filtered, and the first portion of the filtrate was rejected. Part of the remaining filtrate was diluted quantitatively with methanol to obtain the required concentrations for spectrophotometry and HPLC analysis.

\section{Method validation}

The proposed methods were fully validated in terms of linearity, sensitivity, selectivity, accuracy and precision according to the criteria set by the International Conference on Harmonization (ICH) (20) and Food and Drug Administration (FDA) guidelines (21).

Linearity and sensitivity. - Under the specified optimum conditions, the calibration curves for PS and FF were constructed by analyzing a series of concentrations of the standard solutions of the drugs. Assays were performed according to the established general recommended procedures. Regression equations were derived using the least-squares method.

Accuracy and precision. - Accuracy of the second-derivative method for simultaneous determination of pravastatin and fenofibrate was checked at independently prepared concentration levels of 5,10 and $15 \mu \mathrm{g} \mathrm{mL} L^{-1}(n=3)$. Precision of the assays was determined by 
replicate analysis of five sample solutions of the working standards at three concentration levels on the same day and on three different days for each compound. Intra-day precision was expressed through the relative standard deviation of five replicate assays of sample at three concentration levels. Inter-day precision was determined by analyzing the same set of samples on five different days.

On the other hand, accuracy of the proposed HPLC method for simultaneous determination of pravastatin and fenofibrate was checked at independently prepared concentration levels of 7.5, 12.5, 30.0 and $45.0 \mathrm{\mu g} \mathrm{mL}^{-1}(n=3)$. Precision of the assay was determined by replicate analysis of four sample solutions of the working standards at the same day and on three different days. Accuracy and precision of the method were determined for PS and FE according to the FDA guidance for bioanalytical method validation (21). Intra- and inter-day precision was expressed through the relative standard deviation.

Specificity. - Before analyzing the investigated drugs in their pharmaceutical dosage forms, interference liabilities were performed to explore the effect of common excipients that might be added during formulations. Samples were prepared by mixing a known amount of the drug with various amount of common excipients: starch, sucrose, lactose, glucose, magnesium stearate, gum acacia and talc. Analysis of these laboratory-prepared samples was performed using the general recommended procedure and recovery values were determined.

Robustness and ruggedness. - In order to measure the extent of the method robustness, most critical parameters were varied while keeping the other parameters unchanged and, in parallel, the chromatographic profile was observed and recorded. Chromatographic and spectrophotometric parameters were varied within a range of $1-10 \%$ of the optimum recommended conditions. The studied parameters were: the composition of the mobile phase, $\mathrm{pH}$, flow rate and column temperature. Ruggedness of the HPLC and spectrophotometric methods was evaluated by carrying out the analysis using two different analysts and different instruments on different days.

Limit of detection and limit of quantification. - The limit of detection (LOD) and the limit of quantification $(L O Q)(20,22)$ were determined at 3.3 and 10 times the base-line noise, respectively.

\section{RESULTS AND DISCUSSION}

\section{Derivative spectrophotometry}

Absorption spectra. - The zero-order absorption spectra of pravastatin and fenofibrate alone as well as a mixture of the two compounds in methanol are shown in Fig. 2a. The wavelengths of maximum absorbance were found to be 237.6 and $295.1 \mathrm{~nm}$ for PS and FF, respectively. At the same time, the spectra of PS and FF in the mixture displayed overlapping in the region of $200-300 \mathrm{~nm}$. This makes the determination of pravastatin in the presence of fenofibrate by conventional UV spectrophotometry difficult, but the determination of fenofibrate might be possible without interference from pravastatin in the region 300 to $350 \mathrm{~nm}$. 

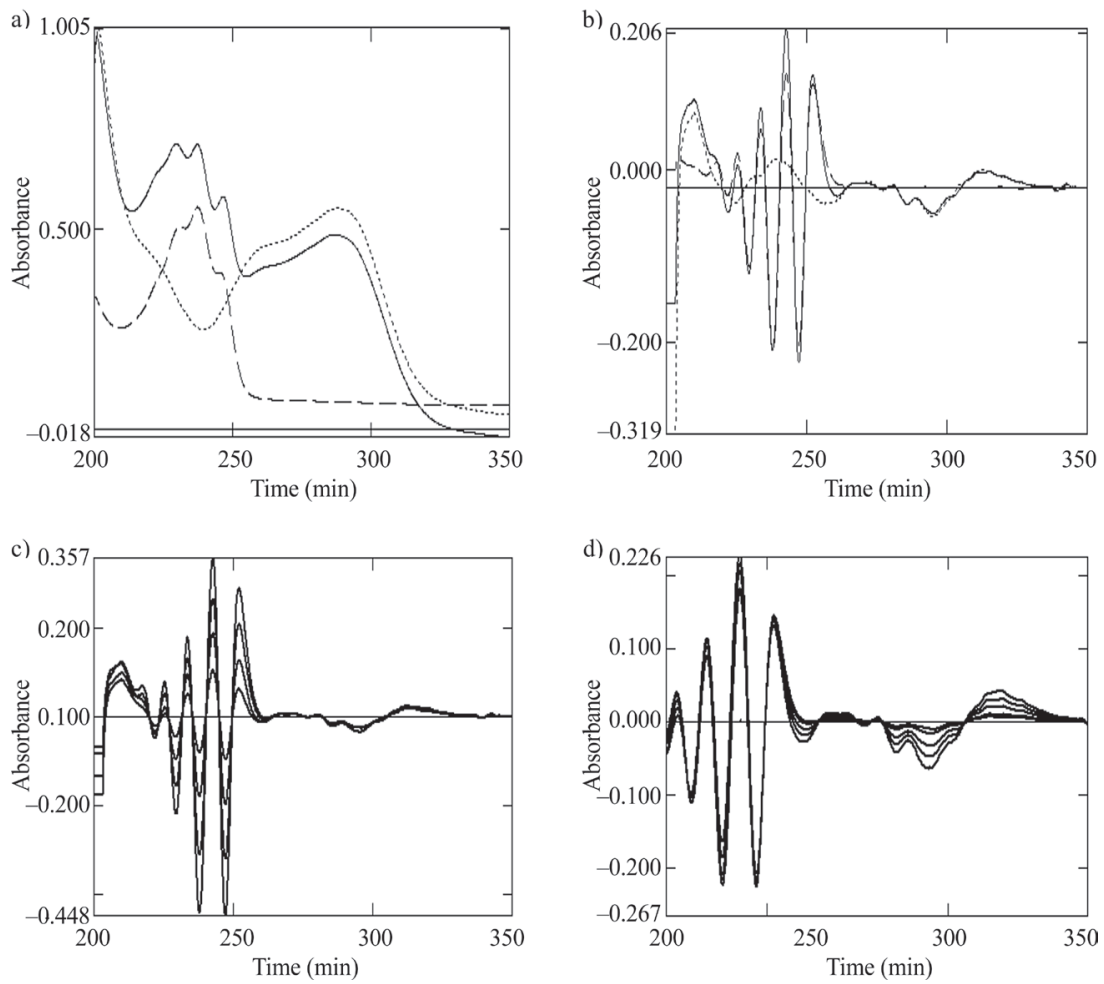

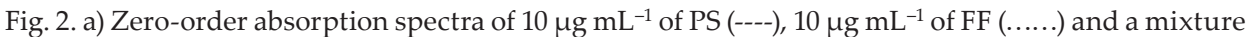
of $10 \mu \mathrm{g} \mathrm{mL}-1$ of each PS and FF (-). b) Second-order derivative absorption spectra of $10 \mu \mathrm{g} \mathrm{mL} \mathrm{mS}^{-1} \mathrm{PS}$ (......), FF (------) and mixture of $10 \mu \mathrm{g} \mathrm{mL} \mathrm{mL}^{-1}$ each PS and FF (-). c) Second-derivative spectra of set of solutions containing $10 \mu \mathrm{g} \mathrm{mL}^{-1}$ of FF and different concentrations of PS $\left(5,10,15\right.$ and $\left.20 \mu \mathrm{g} \mathrm{mL} \mathrm{mL}^{-1}\right)$. d) Second-derivative spectra of the set of solutions containing $10 \mu \mathrm{g} \mathrm{mL}^{-1}$ of PS and different concentrations of FF $\left(3,5,10,15\right.$ and $\left.20 \mu \mathrm{g} \mathrm{mL} \mathrm{m}^{-1}\right)$.

The derivative spectrophotometry technique was, however, chosen for the determination of both drugs since it could remove broadband contributions from excipients and might also overcome the interference from peak overlapping. Derivative spectra of different orders were studied for both pravastatin and fenofibrate individually and simultaneously. The experiments showed that the second-derivative spectra of pravastatin and fenofibrate were simple and gave results with suitable precision at the $\Delta \lambda$ value of $4 \mathrm{~nm}$. In the second-derivative spectra, the signals at $237.6 \mathrm{~nm}$ (zero-crossing point of fenofibrate) are proportional to the pravastatin concentration and the signals at $295.1 \mathrm{~nm}$ (pravastatin reads zero) are proportional to the fenofibrate concentration (Fig. 2b). The tangent method was used for the measurement of peak amplitude at $295.1 \mathrm{~nm}$ (of fenofibrate).

Two sets of solutions were recorded. The first set contained an increasing concentration of PS (5, 10, 15 and $\left.20 \mu \mathrm{g} \mathrm{mL} \mathrm{mL}^{-1}\right)$ and a fixed concentration of FF $\left(10 \mu \mathrm{g} \mathrm{mL}{ }^{-1}\right)$ (Fig. 2c) and the other contained an increasing concentration of $\mathrm{FF}\left(3,5,10,15\right.$ and $\left.20 \mu \mathrm{g} \mathrm{mL}^{-1}\right)$ and 
a fixed concentration of PS $\left(10 \mu \mathrm{g} \mathrm{mL} \mathrm{L}^{-1}\right)$ (Fig. $\left.2 \mathrm{~d}\right)$. The second-derivative spectra of the first set of solutions were found to exhibit two isodifferential points at 237.6 and $295.1 \mathrm{~nm}$. The change in absorbance $\mathrm{d}^{2} A$ with changing wavelength is zero for one component, while the other can be measured at that point without interference of the other. The amplitude for the trough at $237.6 \mathrm{~nm}$ (zero crossing point of $\mathrm{FF}$ ) was found to be proportional to the concentration of PS. Thus, at $237.6 \mathrm{~nm}$ (isodifferential point $\mathrm{d}^{2} A$ /wavelength), PS was determined selectively; at $295.1 \mathrm{~nm}$ (isodifferential point $\mathrm{d}^{2} \mathrm{~A}$ /wavelength) FF was selectively measured. Calibration graphs were prepared by plotting the absorbance at 295.1 in the second-order spectra, against the concentration of PS and FF in their binary solutions, and comparing the values obtained with the pre-constructed calibration graphs for PS and FF.

Method validation. - In all cases, Beer's plot ( $n=3$ number of repetitions of each point) was linear with a very small intercept and good correlation coefficient in the concentration range of 5-20 and 3-20 $\mathrm{gg} \mathrm{mL}^{-1}$ for PS and FF, with the respective correlation coefficients of 0.998 and 0.997 (Table I), indicating good linearity in both cases.

The mean recovery data for each level (at $95 \%$ confidence limit) was between 97.6100.4 and 98.2-101.4 \% for FF and PS, respectively, for intra-day testing. Moreover, interday testing showed the average recovery for FF and PS of 96.2-99.9 and 98.9-99.6\%, respectively. The assays gave satisfactory results with the RSD value in the range $1.0-1.9 \%$. The results are reported in Table II.

Table I. Analytical parameters of the proposed spectrophotometric and HPLC methods for determination of a binary mixture

\begin{tabular}{lcc}
\hline Parameter & PS & FF \\
\hline Linearity range $\left(\mu \mathrm{g} \mathrm{mL}^{-1}\right)$ & $5-20$ & $3-20$ \\
Wavelength $(\mathrm{nm})$ & 237.6 & 295.1 \\
$L O Q\left(\mu \mathrm{g} \mathrm{mL}^{-1}\right)$ & 5.0 & 3.0 \\
$L O D\left(\mu \mathrm{gL}^{-1}\right)$ & 1.5 & 1.0 \\
Slope $\pm \mathrm{RSD}(\%)$ & $0.0032 \pm 1.2$ & $0.00341 \pm 2.9$ \\
Intercept $\pm \mathrm{RSD}(\%)$ & $0.0003 \pm 1.5$ & $-0.01 \pm 2.0$ \\
Molar absorptivity $\left(\mathrm{L} \mathrm{mol}^{-1} \mathrm{~cm}^{-1}\right)$ & $0.9 \times 10^{4}$ & $0.1 \times 10^{5}$ \\
Correlation coefficient $(R)$ & 0.998 & 0.997 \\
\hline & & $20-200$ \\
\hline Linearity range $\left(\mu \mathrm{g} \mathrm{mL} \mathrm{m}^{-1}\right)$ & $5-50$ & 20.0 \\
$L O Q\left(\mu \mathrm{g} \mathrm{mL}{ }^{-1}\right)$ & 5.0 & 6.5 \\
$L O D\left(\mu \mathrm{g} \mathrm{mL}{ }^{-1}\right)$ & 1.5 & $0.022 \pm 5.0$ \\
Slope $\pm \mathrm{RSD}(\%)$ & $0.0548 \pm 5.1$ & $-0.0699 \pm 8.6$ \\
Intercept $\pm \mathrm{RSD}(\%)$ & $-0.0828 \pm 8.6$ & 0.998 \\
Correlation coefficient $(R)$ & 0.999 & \\
\hline
\end{tabular}


M. M. Hefnawy et al.: High-performance liquid chromatography and derivative spectrophotometry for simultaneous determination of pravastatin and fenofibrate in the dosage form, Acta Pharm. 64 (2014) 433-446.

Table II. Accuracy and precision of the proposed spectrophotometric method for determination of a binary mixture (intra-day and inter-day)

\begin{tabular}{rrrrrr}
\hline \multicolumn{7}{c}{ Added $\left(\mu \mathrm{g} \mathrm{mL}^{-1}\right)$} & \multicolumn{2}{c}{ Recovery $(\%)^{\mathrm{a}}$} & \multicolumn{2}{c}{$\left.\mathrm{RSD}^{\mathrm{a}} \%\right)^{\mathrm{a}}$} \\
\hline \multicolumn{7}{c}{ Intra-day } \\
\hline FF & PS & FF & PS & FF & PS \\
5 & 5 & 100.4 & 98.2 & 1.6 & 1.7 \\
10 & 10 & 99.1 & 99.1 & 1.5 & 1.2 \\
15 & 15 & 97.6 & 101.4 & 1.0 & 1.0 \\
\hline \multicolumn{7}{c}{ Inter-day } \\
\hline 5 & 5 & 99.9 & 99.6 & 1.8 & 1.9 \\
10 & 10 & 98.8 & 98.8 & 1.5 & 1.5 \\
15 & 15 & 98.3 & 99.4 & 1.4 & 1.2 \\
\hline
\end{tabular}

a Average of three replicates.

The results indicate that there was no interference from the excipients used; recovery values were $97.5 \%$ for FF and PS with the RSD value of 0.8 and $0.6 \%$, respectively. This indicates the absence of interference liabilities from the excipients.

The results obtained from lab-to-lab (two different laboratories) and day-to-day (different elapsed times) were found to be reproducible. The average recoveries were between 97.6-100.4 and $98.2-101.4 \%$ for FF and PS, respectively. The average recovery value was higher than $97.0 \%$.

HPLC

Method development. - Various mobile phases and stationary phases were tested in an attempt to obtain the best separation and resolution among PS, FF and internal standard. Different compositions of the mobile phase were studied in order to shorten retention times of the analyte and to improve peak symmetry; best results were obtained using acetonitrile/0.1\% diethylamine $(50: 50, V / V)$ as a mobile phase. The $\mathrm{pH}$ of the mobile phase was adjusted with $20 \%$-phosphoric acid to $\mathrm{pH} 4.5$.

System suitability. - Capacity factor $(k ')$, asymmetry of the peaks, number of theoretical plates, the height equivalent to the theoretical plate, tailing factor and resolution between two consecutive peaks were evaluated. Results of system suitability testing are presented in Table III. The peaks of PS, FF and IS were well resolved, with retention times of 2.15, 5.79 and $14.0 \mathrm{~min}$, respectively. Analysis was achieved within $18 \mathrm{~min}$ for a total chromatography run. A good resolution was obtained between two consecutive peaks in the developed method. The capacity factor, separation factor and tailing factor were 46.93 and 158.73, 1.25 and 3.38 and 1.14 and 1.05, respectively, for PS and FF.

Method validation. - The results indicated that there was no interference from the excipients used; recovery values were $97.0-98.3 \%$ with the RSD value of $0.3-0.6 \%$. This in- 
a)
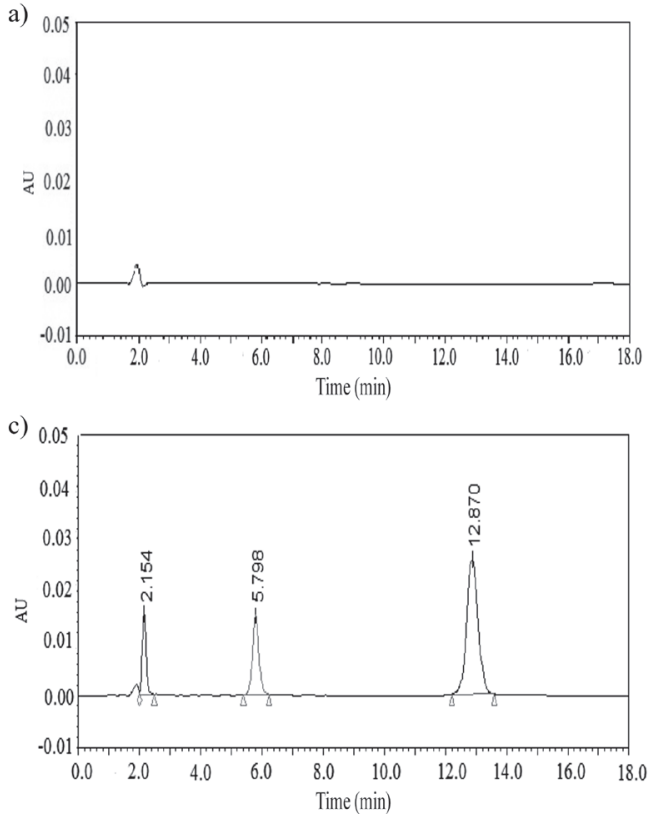

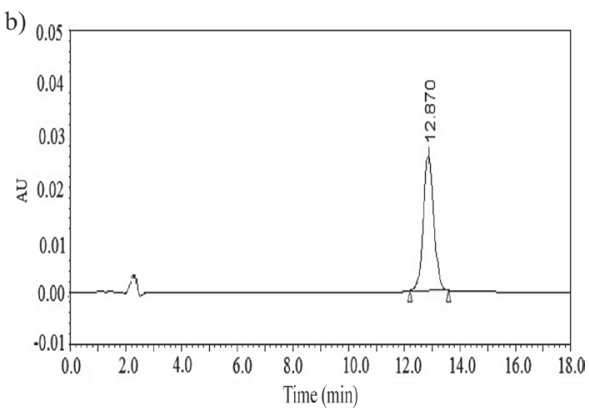

Fig. 3. HPLC chromatograms of: a) blank sample, b) blank sample spiked with $100 \mu \mathrm{g} \mathrm{mL}^{-1}$ of darifenacin (IS) and c) Pravafenix capsule sample (containing $4 \mu \mathrm{g} \mathrm{mL}^{-1}$ of pravastatin and $20 \mu \mathrm{g} \mathrm{mL}^{-1}$ of fenofibrate) and $100 \mu \mathrm{g} \mathrm{mL}^{-1}$ of darifenacin (IS).

Table III. Chromatographic parameters for PS and FF by the proposed HPLC method

\begin{tabular}{lcc}
\hline Parameter & PS & FF \\
\hline Retention time $(\mathrm{min})$ & 2.15 & 05.79 \\
Capacity factor $\left(k^{\prime}\right)$ & 46.930 & 158.730 \\
Separation factor $(\alpha)$ & 1.25 & 03.38 \\
Resolution factor $\left(R_{\mathrm{s}}\right)$ & 1.50 & 14.95 \\
Number of theoretical plates $(N)$ & 1723.60000 & 4053.0100 \\
HETP $(\mu \mathrm{m})$ & 72.520 & 30.84 \\
Tailing factor (asymmetry factor) & 1.14 & 01.05 \\
\hline
\end{tabular}

$k^{\prime}$ - the average retention factor for the two bands.

The column plate number was determined using the formula: $N=5.54\left(t_{\mathrm{R}} / w_{\mathrm{h}}\right)^{2}$, where $w_{\mathrm{h}}$ is the bandwidth at $50 \%$ of peak height.

dicates the absence of interference liabilities from these excipients. Figs. 3a and b show chromatograms of placebo spiked with $100 \mu \mathrm{g} \mathrm{mL} \mathrm{L}^{-1}$ of internal standard. Fig. 3c shows the chromatogram of the drug formulation with 4 and $20 \mu \mathrm{gL}^{-1}$ of PS and FF, respectively, and $100 \mu \mathrm{g} \mathrm{mL} \mathrm{g}^{-1}$ IS. No endogenous peak from placebo was found to interfere with the PS, 
M. M. Hefnawy et al.: High-performance liquid chromatography and derivative spectrophotometry for simultaneous determination of pravastatin and fenofibrate in the dosage form, Acta Pharm. 64 (2014) 433-446.

Table IV. Intra-day and inter-day reproducibility of a model sample of pravastatin and fenofibrate obtained by HPLC

\begin{tabular}{ccccc}
\hline \multirow{2}{*}{$\begin{array}{c}\text { Concentration } \\
\left(\mu \mathrm{g} \mathrm{mL}^{-1}\right)\end{array}$} & \multicolumn{2}{c}{ Intra-day } & \multicolumn{2}{c}{ Inter-day } \\
\cline { 2 - 5 } & Accuracy $(\%)$ & RSD $(\%)$ & Accuracy $(\%)$ & RSD $(\%)$ \\
\hline \multicolumn{5}{c}{ PS } \\
\hline 7.5 & 102.6 & 0.6 & 97.3 & 0.7 \\
12.5 & 97.6 & 0.3 & 97.6 & 0.3 \\
30.0 & 101.6 & 0.2 & 100.00 & 1.6 \\
45.0 & 102.0 & 0.7 & 101.70 & 1.1 \\
\hline \multicolumn{5}{c}{ FF } \\
\hline 30.0 & 97.3 & 0.7 & 97.0 & 1.1 \\
50.0 & 97.4 & 0.4 & 97.2 & 0.7 \\
120.00 & 98.3 & 0.6 & 98.1 & 0.7 \\
180.00 & 98.9 & 0.8 & 98.3 & 0.5 \\
\hline
\end{tabular}

Table $V$. Effects of experimental parameters on the recovery of PS and FF

\begin{tabular}{|c|c|c|c|}
\hline \multirow{2}{*}{ Parameter } & \multirow{2}{*}{ Modification } & \multicolumn{2}{|c|}{ Recovery (\%) } \\
\hline & & PS & FF \\
\hline \multirow{3}{*}{ Flow rate $\left(\mathrm{mL} \mathrm{min}^{-1}\right)$} & 0.9 & 101.1 & 98.5 \\
\hline & 1.0 & 100.9 & 99.0 \\
\hline & 1.1 & 96.3 & 97.3 \\
\hline \multirow{3}{*}{ Injection volume $(\mu \mathrm{L})$} & 8.0 & 97.6 & 98.0 \\
\hline & 10.0 & 99.8 & 98.5 \\
\hline & 15.0 & 98.1 & 96.7 \\
\hline \multirow{3}{*}{$\mathrm{pH}$} & 4.0 & 100.2 & 100.0 \\
\hline & 4.5 & 96.2 & 97.5 \\
\hline & 4.7 & 98.0 & 98.0 \\
\hline \multirow{3}{*}{ Day $^{\mathrm{a}}$} & 1.0 & 100.1 & 99.0 \\
\hline & 2.0 & 100.3 & 98.0 \\
\hline & 3.0 & 99.7 & 98.5 \\
\hline \multirow{4}{*}{ Temperature $\left({ }^{\circ} \mathrm{C}\right)$} & 25.0 & 99.3 & 98.5 \\
\hline & 30.0 & 99.1 & 97.5 \\
\hline & 35.0 & 98.6 & 99.0 \\
\hline & -80.0 & 97.5 & 98.0 \\
\hline \multirow{2}{*}{ Analyst } & 1.0 & 98.8 & 98.0 \\
\hline & 2.0 & 98.1 & 98.7 \\
\hline
\end{tabular}

a Solution was stored at room temperature. 
M. M. Hefnawy et al.: High-performance liquid chromatography and derivative spectrophotometry for simultaneous determination of pravastatin and fenofibrate in the dosage form, Acta Pharm. 64 (2014) 433-446.

FF or IS elution. The peaks were in good shape and completely separated one from the other.

Linear relationship was demonstrated between peak area ratios of both PS and FF over IS and drug concentrations over a range of 5-50 and 20-200 $\mu \mathrm{g} \mathrm{mL} \mathrm{m}^{-1}$, respectively, with the correlation coefficient $(R)$ of 0.999 and 0.998 . Table I summarizes the precision of calibration curve parameters. The LOQ of PS and FF were estimated as 5 and $20 \mu \mathrm{gL}^{-1}$, at which the accuracy was between $97.0-98.5 \%$ and precision was less than $2 \%$. Limit of detection $(L O D)$ was 1.5 and $6.5 \mu \mathrm{g} \mathrm{mL^{-1 }}$ resp. (21).

Accuracy and precision. - The RSD values of intra-day (0.6-0.7 and 0.4-0.8\%) and interday (0.3-1.1 and 0.5-1.1\%) studies for PS and FF showed that the precision of the method was satisfactory (Table IV). Accuracy of the analytical method used was $97.0-98.9 \%$ for intra- and inter-day, respectively.

Model samples of PS and FF were used for stability experiments. Stability was assessed under a variety of conditions. No evidence of degradation was noticed during sample processing and storing for at least one month, in a freezer at $-80{ }^{\circ} \mathrm{C}$. No effects of short term stability of frozen samples kept at room temperature for $6 \mathrm{~h}$ on quantification of PS and FF were observed. These studies suggest that the samples containing both drugs can be handled under normal laboratory conditions without any significant loss of drugs (Table V).

Results obtained using two different analysts and different instruments were found to be reproducible. An error not greater than $4 \%$ was observed (Table V).

\section{Application to dosage forms}

The two proposed methods were applied to the determination of PS and FF in their commercial dosage form and in a laboratory prepared formulation (see Experimental). Satisfactory results were obtained and are in good agreement with the reported methods $(4,12)$ (Table VI). There was no significant difference between the two proposed methods and between either of them and the reference methods with regard to accuracy and precision.

\section{CONCLUSIONS}

The present study investigates for the first time the development of two methods (HPLC and second-derivative spectrophotometry) for the simultaneous determination of PS and FF in pharmaceutical formulations. The methods are rapid, accurate and reliable, without interference from common excipients. Due to their simplicity and sufficient sensitivity, the proposed methods can be used in quality control laboratories. The advantage of the derivative spectrophotometric method over the HPLC method is its low cost. On the other hand, the advantage of HPLC over the derivative spectrophotometry is its selectivity and applicability to the analysis of drugs in a variety of matrices.

Acknowledgements. - The authors extend their appreciation to the Deanship of Scientific Research at King Saud University for funding the work through the research group project No. RGP-VPP-037. 
M. M. Hefnawy et al.: High-performance liquid chromatography and derivative spectrophotometry for simultaneous determination of pravastatin and fenofibrate in the dosage form, Acta Pharm. 64 (2014) 433-446.

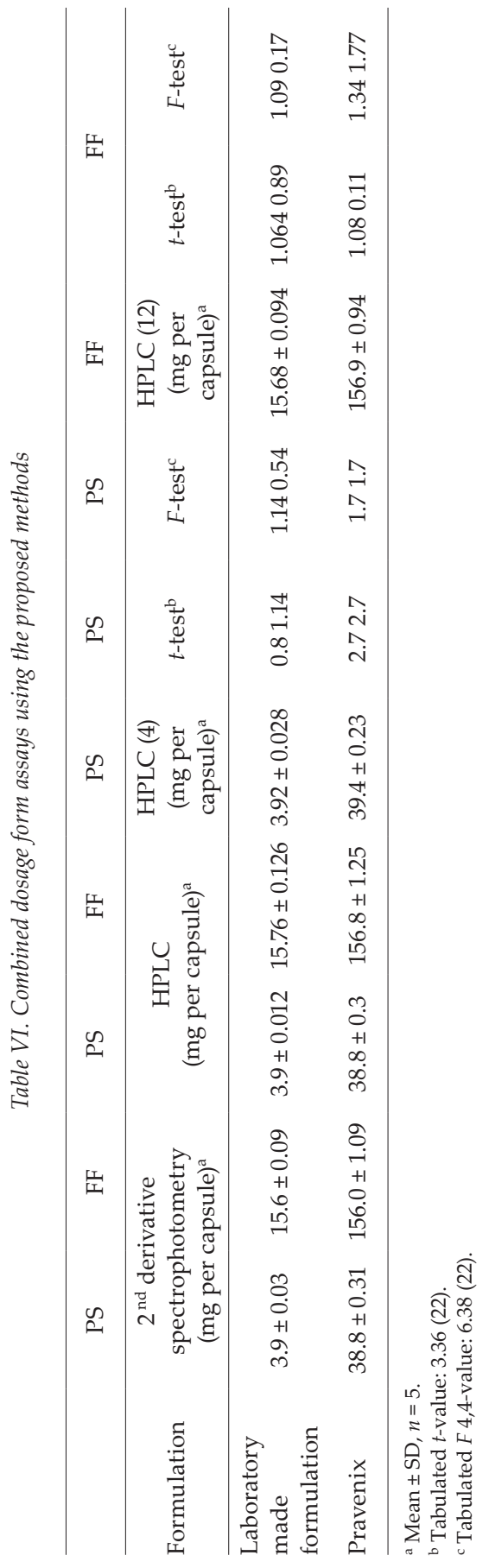


M. M. Hefnawy et al.: High-performance liquid chromatography and derivative spectrophotometry for simultaneous determination of pravastatin and fenofibrate in the dosage form, Acta Pharm. 64 (2014) 433-446.

\section{REFERENCES}

1. A. A. Al-Badr and G. A. E. Mostafa, Pravastatin sodium, Comprehensive Profile, Prof. Drug Subst. Exc. Rel. Meth. 39 (2014) 433-513.

2. M. Farnier, Pravastatin and fenofibrate in combination (Pravafenix ${ }^{\circledR}$ ) for the treatment of high-risk patients with mixed hyperlipidemia, Expert Rev. Cardiovasc. Ther. 11 (2013) 253-254; DOI: 10.1586/ erc.12.191.

3. S. Bauer, J. Mwinyi, A. Stoeckle, T. Gerloff and I. Roots, Quantification of pravastatin in human plasma and urine after solid phase extraction using high performance liquid chromatography with ultraviolet detection, J. Chromatogr. B 818 (2005) 257-262; DOI: 10.1016/j.jchromb.2005.01.006.

4. T. D. Silva, M. A. Oliveira, R. B. de Oliveira and C. D. Vianna-Soares, Development and validation of a simple and fast HPLC method for determination of lovastatin, pravastatin and simvastatin, J. Chromatogr. Sci. 50 (2012) 831-838; DOI: 10.1093/chromsci/bms079.

5. R. Siekmeier, W. Gross and W. März, Determination of pravastatin by high performance liquid chromatography, Int. J. Clin. Pharmacol. Ther. 38 (2000) 419-425.

6. H. Vlčková, M. Rabatinová, A. Mikšová, G. Kolouchová, S. Mičuda, P. Solich and L. Nováková, Determination of pravastatin and pravastatin lactone in rat plasma and urine using UHPLC-MS/ MS and microextraction by packed sorbent, Talanta 90 (2012) 22-29; DOI: 10.1016/j.talanta.2011.12.043.

7. Z. Zhu and L. Neirinck, High-performance liquid chromatography coupled with negative ion tandem mass spectrometry for determination of pravastatin in human plasma, J. Chromatogr. B 783 (2003) 133-140; DOI: 10.1016/S1570-0232(02)00526-3.

8. D. Mulvana, M. Jemal and S. C. Pulver, Quantitative determination of pravastatin and its biotransformation products in human serum by turbo ion spray LC/MS/MS, J. Pharm. Biomed. Anal. 23 (2000) 851-866, DOI: 10.1016/S0731-7085(00)00372-1.

9. K. Kawabata, N. Matsushima and K. Sasahara, An automated method for the simultaneous determination of pravastatin and its main metabolite in human plasma by high-performance liquid chromatography/atmospheric pressure chemical ionization mass spectrometry, Biomed. Chromatogr. 12 (1998) 271-275; DOI: 10.1002/(SICI)1099-0801(199809/10)12:5 < 27.

10. B. Nigović, Electrochemical properties and square-wave voltammetric determination of pravastatin, Anal. Bioanal. Chem. 384 (2006) 431-437.

11. United States Pharmacopoeia 30, USP Convention Inc., Rockville, 2007.

12. British Pharmacopoeia 2004, The Stationary Office, London 2004, p. 639.

13. R. J. Straka, R. T. Burkhardt and J. E. Fisher, Determination of fenofibric acid concentrations by HPLC after anion exchange solid-phase extraction from human serum, Ther. Drug Monit. 29 (2007) 197-202; DOI: 10.1097/ftd.0b013e318030860a.

14. A. A. Kadav and D. N. Vora, Stability indicating UPLC method for simultaneous determination of atorvastatin, fenofibrate and their degradation products in tablets, J. Pharm. Biomed. Anal. 48 (2008) 120-126; DOI: 10.1016/j.jpba.2008.05.018.

15. D. Bhavesh, S. Shah and Shivprakash, Determination of fenofibric acid in human plasma by ultra performance liquid chromatography-electrospray ionization mass spectrometry: application to a bioequivalence study, Biomed. Chromatogr. 23 (2009) 922-928, DOI: 10.1002/bmc.1203.

16. C. Yardimci and N. Ozaltin, Electrochemical studies and square-wave voltammetric determination of fenofibrate in pharmaceutical formulations, Anal. Bioanal. Chem. 378 (2004) 495-498; DOI: 10.1007/s00216-003-2246-x.

17. M. A. Korany, I. I. Hewala and K. M. Abdel-Hay, Determination of etofibrate, fenofibrate, and atorvastatin in pharmaceutical preparations and plasma using differential pulse polarographic and square wave voltammetric techniques, J AOAC Int. 91 (2008) 1051-1058. 
18. P. D. Anumolu, N. S. Bhavani, P. S. Babu and C. Sburahmanyam, A validated spectral discri-minating derivative spectrophotometric method for simultaneous quantification of atorvastatin calcium and fenofibrate combination in tablets, Orint. J. Chem. 29 (2013) 1605-1610, DOI: 10.13005/ ojc/290444.

19. A. Patel, C. Macwana, V. Pamar and S. Patel, Simultaneous determination of atorvastatin calcium, ezetimibe, and fenofibrate in tablet formulation by HPLC, JAOAC 95 (2012) 419-423.

20. International Conference on Harmonization of Technical Requirements for Registration of Pharmaceuticals for Human Use, ICH Harmonised Tripartite Guideline, Validation of Analytical Procedures: Text and Methodology Q2 (R1), ICH Complementary Guideline on Methodology dated 06 November 1996, incorporated in November 2005, London.

21. FDA Guidance for Industry: Bioanalytical Method Validation, US Department of Health and Human Services, Food and Drug Administration, Center for Drug Evaluation and Research (CDER), Center for Biologics Evaluation and Research (CBER), Rockville (MD) 2001.

22. J. N. Miller and J. C. Miller, Statistics and Chemometrics for Analytical Chemistry, $2^{\text {nd }}$ ed., Pearson Education Limited, Harlow 2005. 